\title{
Evidence of osmoregulation in Larix decidua at Alpine treeline and comparative responses to water availability of two co-occurring evergreen species
}

\author{
Alessandro Badalottia ${ }^{\mathrm{a},}$, Tommaso Anfodillo ${ }^{\mathrm{b}}$ and John Grace ${ }^{\mathrm{a}}$ \\ a University of Edinburgh, Institute of Ecology and Resource Management, Darwin Building, Mayfield Road, \\ Edinburgh EH9 3JU, Scotland, U.K. \\ b Dipartimento Territorio e Sistemi Agro Forestali, University of Padova, Agripolis, Via Romea, 16, 35020 Legnaro (PD), Italy
}

(Received 18 November 1999; accepted 12 May 2000)

\begin{abstract}
The water relations of three coniferous species (Larix decidua, Picea abies and Pinus cembra) growing at a treeline ecotone in the Southern Alps were investigated. Sap flux and xylem water potential were measured in two individuals of each of the above-mentioned species during part of summer 1997. Throughout the growing period, L. decidua showed a gradual decrease in minimum water potential while for P.abies and P. cembra, variations were more correlated to actual weather conditions. Daily sap flux was also higher in L. decidua than in the two other species. Pressure-volume curves derived for L. decidua during July 1997 demonstrated that the species further diminished its minimum water potential through osmoregulation. During dry periods the other species showed an evident reduction in sap flux suggesting a water saving behaviour. The three species seem therefore to have evolved different drought avoidance strategies.
\end{abstract}

osmotic adjustment / Pinus cembra / Picea abies / sap flow / pressure-volume curves

Résumé - Évidence d'un ajustement osmotique chez Larix decidua à la limite de l'étage forestier alpin et réponses comparées à la disponibilité en eau de deux espèces de conifères co-existantes. On a étudié les stratégies hydriques de trois espèces de conifères (Larix decidua, Picea abies et Pinus cembra) qui poussent dans un écotone à la limite supérieure de l'étage forestier dans le sud des Alpes. On a mesuré le flux de sève et le potentiel hydrique du xylème pour deux individus des espèces citées précédemment pendant une partie de l'été 1997. Durant la période de végétation, L. decidua a montré une diminution progressive du potentiel hydrique minimum tandis que les variations de P.abies et de P. cembra étaient corrélées en grande partie aux conditions atmosphériques. Le flux de sève journalier aussi était plus important chez L. decidua que dans les deux autres espèces. Les courbes pression-volume établies pour L. decidua au mois de juillet 1997 montrent que l'espèce est en mesure de diminuer ultérieurement son potentiel hydrique minimum à travers un ajustement osmotique. Pendant les périodes de sècheresse, les autres espèces ont manifesté une réduction visible du flux de sève suggérant ainsi un comportement adapté pour limiter la consommation d'eau. Les trois espèces semblent donc avoir développé des stratégies différentes pour éviter la sécheresse.

ajustement osmotique / Pinus cembra / Picea abies / flux de sève / courbes pression-volume

*Correspondence and reprints

Tel. 0131650 5437; Fax. 0131662 0478; e-mail: abadalotti@ hotmail.com 


\begin{tabular}{ll}
\multicolumn{2}{c}{ Abbreviations } \\
$F_{\mathrm{d}}:$ & Sap flux density $\left(\mathrm{dm}^{3} \mathrm{dm}^{-2} \mathrm{~h}^{-1}\right)$ \\
PAR: & Photosynthetic active radiation $\left(\mu \mathrm{mol} \mathrm{m} \mathrm{m}^{-2} \mathrm{~s}^{-1}\right)$ \\
$R:$ & Hydraulic resistance $\left(\mathrm{MPa} \mathrm{dm}^{-1} \mathrm{~h}\right)$ \\
RTLP: & Relative water content at turgor loss point \\
RWC: & Relative water content \\
VPD: & Vapour pressure deficit $(\mathrm{hPa})$ \\
WPTLP: & Water potential at turgor loss point $(\mathrm{MPa})$ \\
$\varepsilon_{\mathrm{max}}:$ & Maximum elastic modulus \\
& of the cell wall $(\mathrm{MPa})$ \\
$\Psi_{0}:$ & Xylem water potential $(\mathrm{MPa})$ \\
$\Psi_{\mathrm{m}}:$ & Minimum xylem water potential $(\mathrm{MPa})$ \\
$\Psi_{\text {pd }}:$ & Predawn xylem water potential $(\mathrm{MPa})$ \\
$\Psi_{\pi}:$ & Osmotic potential $(\mathrm{MPa})$ \\
$\Psi_{\pi 100}:$ & Osmotic potential at full turgor $(\mathrm{MPa})$
\end{tabular}

\section{INTRODUCTION}

In the last few years a renewed interest in the physiology of plants growing at treeline has been sparked by the realisation that global climate change could have a marked effect on the treeline ecotone [3, 13]. Treelines are controlled by a range of environmental factors in different parts of the world with temperature usually identified as the main one [15]. The treelines of the Alps appear to be determined, at least in part, by winter and spring desiccation of needles when the soil is frozen. This has been attributed to an incomplete development of the needle cuticle during the short growing period [30, 37 , although this is not usually the case in more maritime regions [10, 11].

Recent evidence suggests that climate changes can affect the distribution of plant communities and shift the range of various alpine species $[19,21]$ and climate warming has been thought to be the cause of an altitudinal shift upwards in alpine plants [9]. However, no evident effects of recent higher summer temperatures on altitudinal range have been recorded in alpine Pinus sylvestris and Pinus cembra [14]. A better understanding of tree physiology at the treeline is needed in order to predict possible future scenarios brought about by climate change. Indirect effects (such as the duration of snow cover or the amount of water in the soil) appear to be more important than direct temperature effects on life processes [18]. Climate scenarios suggest lower rainfall and more frequent droughts [36], which may influence species distributions as a consequence of species variability in water relations [7]. It follows that the seasonal monitoring of water status in trees at treeline should increase our understanding over how climate change can affect their distribution. Recently, drought resistance mechanisms of different species at treeline have been studied in the Southern Alps [2]. Although trees growing at the alpine treeline only rarely undergo severe water stress because of high precipitation during the vegetative period, moderate water deficits may lead to a strong reduction of transpiration due to a high stomatal sensitivity to drought. Tree species found at treeline show a well-developed water-saving behaviour, probably induced by the low soil water content due to the shallow mountain soils. Some species (such as Larix decidua) appear to cope with these moderate water deficits better than others (Picea abies and $P$. cembra). Studies carried out on a treeline ecotone in the Italian Alps hypothesised the occurrence of osmoregulation in L. decidua during periods of drought. Osmoregulation can contribute to the maintenance of turgor during periods of water stress and could therefore increase the chances of this species to compete with the other treeline species for the colonisation of the alpine areas rendered suitable to seedling establishment in the case of climate warming. In this article we will discuss the importance of this phenomenon in relation to drought response and competitive abilities of these three species.

\section{MATERIALS AND METHODS}

\subsection{Study site}

The experiments were conducted on a treeline ecotone (sensu Crawford [5]) at $2080 \mathrm{~m}$ above sea level in the Southern Alps (Italian Dolomites, Cortina d'Ampezzo). The site has a Southern aspect and 30\% slope, with shallow calcareous soil. The treeline is formed by mixed stands of relatively young L. decidua, P. cembra and $P$. abies which are invading edges of recently abandoned pasture [8]. June-September mean precipitation is 450-500 mm.

Six trees (the same ones used in another study [2] during 1996) were used for the experiment, two for each of the above-mentioned species (table I).

\subsection{Xylem water potential}

Xylem water potential $(\Psi)$ was measured for seven days (from 1 July to 23 August 1997; days 182-235) on 1 -year-old shoots. Two shoots were collected at a height of $2 \mathrm{~m}$ on each tree from predawn $\left(\Psi_{\mathrm{pd}}\right)$ to dusk at intervals of 2 hours and measurements were made directly at the site with a pressure chamber within two minutes of collection. Data were then averaged since no significant $(p=n s)$ statistical difference was recorded between individuals of the same species (table III). 
Table I. Main features of the sampled trees including their age as calculated from sample cores the year before the study, their diameter at breast height $(1.3 \mathrm{~m})$ and their height.

\begin{tabular}{lccr}
\hline Tree & $\begin{array}{c}\text { Age } \\
\text { (years) }\end{array}$ & $\begin{array}{c}\text { Diameter } \\
\text { at breast height }(\mathrm{cm})\end{array}$ & $\begin{array}{c}\text { Height } \\
(\mathrm{m})\end{array}$ \\
\hline L. decidua \#1 & 38 & 24.2 & 10.2 \\
L. decidua \#2 & 59 & 25.1 & 9.6 \\
P. abies \#1 & 54 & 25.1 & 9.3 \\
P. abies \#2 & 53 & 30.9 & 11.1 \\
P. cembra \#1 & 36 & 27.3 & 7.2 \\
P. cembra \#2 & 47 & 33.4 & 7.9 \\
\hline
\end{tabular}

\subsection{Sap flux density}

Xylem sap flux density $\left(F_{\mathrm{d}}, \mathrm{dm}^{3} \mathrm{dm}^{-2} \mathrm{~h}^{-1}\right)$ was measured in each tree using $2 \mathrm{~cm}$ continuously-heated sap flowmeters [12]. Sensors were inserted into the xylem (NW aspect) at 1.5-2 m. Measurements were taken every minute, averaged and stored every 15 minutes using a storage module connected to a datalogger (CR10, Campbell Ltd, Lincoln, Nebraska). Protection from high solar radiation was ensured, both by insulating shields placed over the sensors in the case of L. decidua and by the dense tree crowns reaching to the ground for $P$. abies and $P$. cembra. Sap flux density was measured from 17 June to 13 October 1997 (days 168-286). Sapwood area and total tree transpiration were not estimated because of the uncertainty in defining the number of active tree rings and the contribution of each of them to the total water transport.

\subsection{Hydraulic resistance}

The sapwood-specific hydraulic resistance between soil and needles was calculated from the relationship between needle water potential and sap flux density:

$$
R_{\text {soil-needle }}=\frac{\left(\Psi_{\text {needle }}-\Psi_{\text {soii }}\right)}{F_{\mathrm{d}}}
$$

Where $R_{\text {soil-needle }}$ is the sapwood-specific hydraulic resistance between soil and needles ( $\left.\mathrm{MPa} \mathrm{dm}{ }^{-1} \mathrm{~h}\right), \Psi_{\text {soil }}$ and $\Psi_{\text {needle }}$ are the soil and needle water potential respectively (MPa) and $F_{\mathrm{d}}$ the sap flux density $\left(\mathrm{dm}^{3} \mathrm{dm}^{-2} \mathrm{~h}^{-1}\right)$.

\subsection{Pressure-volume curves}

Ten pressure-volume curves were derived for L. decidua at the site and two for P. cembra at irregular intervals in the period between 29 June and 2 August (days 180-214). Samples were always taken from the $S$ exposed canopy at a height of $1.5-2.5 \mathrm{~m}$ from the ground in the evening hours of the day previous to the day of the measurement, sealed in a polythene bag to reduce evaporative loss of water and taken to the laboratory. Here cut ends of the shoots were immersed in water and the shoots were left rehydrating for 12-15 hours in the darkness for the whole night [26, 34].

The pressure-volume curves were constituted as the standard method described in the literature [33] suggests, collecting data by using a pressure chamber [28]. A wet piece of blotting paper was enclosed in the pressure chamber in order to prevent evaporative loss during the measurements [31,34]. Pressure was increased slowly $\left(0.01 \mathrm{MPa} \mathrm{s}^{-1}\right)$ during the measurements, until a droplet of xylem sap appeared on the section of the shoot.

In some samples $\Psi$ remained almost constant with tissue dehydration in the region of high turgor potential [25]. This particular "plateau effect" is believed to be an artefact caused by oversaturation of samples [20] even if observed in naturally rehydrated plants [25].

In order to minimise the plateau effect, the raw data were plotted and, after having excluded the points where this effect was evident, the real saturated weight $(\Psi=0)$ of the shoots was extrapolated using a linear regression of fresh weight against balance pressure as suggested in the literature [22].

Curves were then analysed using a segmented nonlinear regression algorithm [26] fitted on a modified exponential model described in the literature [29]. When the plateau effect was minimum the model used fitted the experimental data very well (figure 1). In other cases a slight difference appeared in the region of high turgor pressure. However, for all curves, the variance explained from the model exceeded 0.972 (table II). All curves and parametric values inferred from them were derived separately and then averaged for display in the figures. This was not possible for L. decidua for day 208 and 212, in which only one curve was available.

\subsection{Microclimate}

Standard meteorological variables above the canopy (global radiation, air temperature, relative humidity, wind velocity and direction, rainfall and photosynthetic active radiation) were monitored every minute, averaged and stored every 15 minutes with a datalogger (Campbell 
Ltd CR10) connected to two multiplexers (Campbell AM32). A solar panel (Helios technology $50 \mathrm{~W}$ ) and batteries (140 Ah) provided power.

\subsection{Soil water}

Relative soil moisture content was measured with time domain reflectometry (Campbell CS615) at $30 \mathrm{~cm}$ depth with a water content reflectometer from 11 June (day 162) to 13 October (day 286). These measurements are expressed as relative values in relation to the maximum value recorded after high precipitation occurred (i.e. relative soil water content compared to soil holding capacity).

\section{RESULTS}

During summer 1997 (June-September) an aboveaverage rainfall of $652.6 \mathrm{~mm}$ was recorded (figure $2 a$ ). However, an unusually dry period occurred from 9 September (day 252) to 13 October (day 286 and end of the measurements) (figure $2 b$ ).

The maximum mean air temperature was reached at the beginning of September (about $15^{\circ} \mathrm{C}$ ), just after a cool spell at the end of August.

\subsection{Shoot water potential}

Figure 3 shows the seasonal course of predawn water potential $\left(\Psi_{\mathrm{pd}}\right)$ and minimum water potential $\left(\Psi_{\mathrm{m}}\right)$ for the selected trees. $P$. abies was the species with the highest values of $\Psi_{\text {pd }}$, dropping below $-0.4 \mathrm{MPa}$ only during August and maintaining a fairly constant value throughout the study period. L. decidua and P. cembra showed parallel variations for most of July (days 182-204). While in P. cembra $\Psi_{\mathrm{pd}}$ became less negative at the end of July, in L. decidua it continued to decrease to a minimum (-1.07 MPa) at the end of August (day 235).

Minimum water potentials $\left(\Psi_{\mathrm{m}}\right)$ of $P$. abies and $P$. cembra displayed parallel time courses during most of July (days 190-211). However, while P. abies reached its minimum (-1.48 MPa) at the end of August (day 235), the minimum for $P$. cembra $(-1.28 \mathrm{MPa})$ was reached at the end of July (day 211). L. decidua $\Psi_{\mathrm{m}}$ continued to decrease throughout the study period, with a different pattern than in the other two species and reaching its minimum (-2.23 MPa) at the end of August (day 235).

Different statistical tests showed that there was a highly significant effect of species and, in some cases, time of the season on the values of $\Psi_{\mathrm{pd}}$ and $\Psi_{\mathrm{m}}$ (table III). However, differences between individuals were not significant.
Table II. Values of the variance explained $\left(R^{2}\right)$ of each of the pressure-volume curves drawn. $a=$ Larix decidua, $b=$ Pinus cembra.

\begin{tabular}{lcl}
\hline Date & Day of year & $R^{2}$ \\
\hline$a$ & & \\
29-Jun & 180 & 0.998 \\
29-Jun & 180 & 0.99 \\
16-Jul & 197 & 0.972 \\
16-Jul & 197 & 0.98 \\
27-Jul & 208 & 0.992 \\
31-Jul & 212 & 0.998 \\
02-Aug & 214 & 0.972 \\
02-Aug & 214 & 0.986 \\
$b$ & & \\
01-Aug & 213 & 0.999 \\
01-Aug & 213 & 0.998 \\
\hline
\end{tabular}

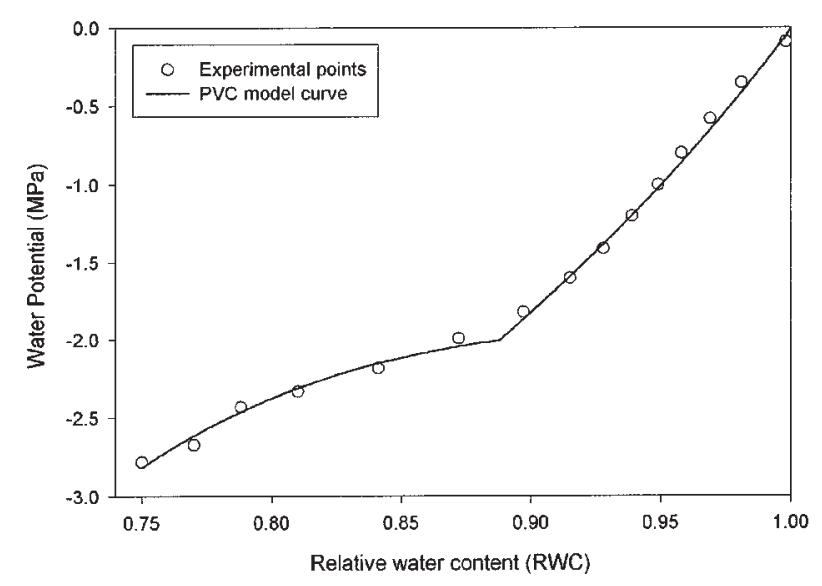

Figure 1. Example of accuracy of model (line) derived pressure-volume curve and experimentally derived data (points) for day 180 (29 June).

\subsection{Daily and seasonal variations in sap flux density}

Daily fluctuations in water potential, in relation to meteorological parameters and sap flux density, are shown for two representative days in figure 4. Because of the frequent and rapid variations in cloudiness at high altitude, air temperature, vapour pressure deficit (VPD) and solar radiation changed abruptly.

Sap flux of all species was visibly coupled with VPD. In L. decidua $F_{\mathrm{d}}$ increased sharply and reached the daily maximum by mid morning. $\Psi$ decreased rapidly and $\Psi_{\mathrm{m}}$ was usually reached by 10 AM. Once the minimum was 


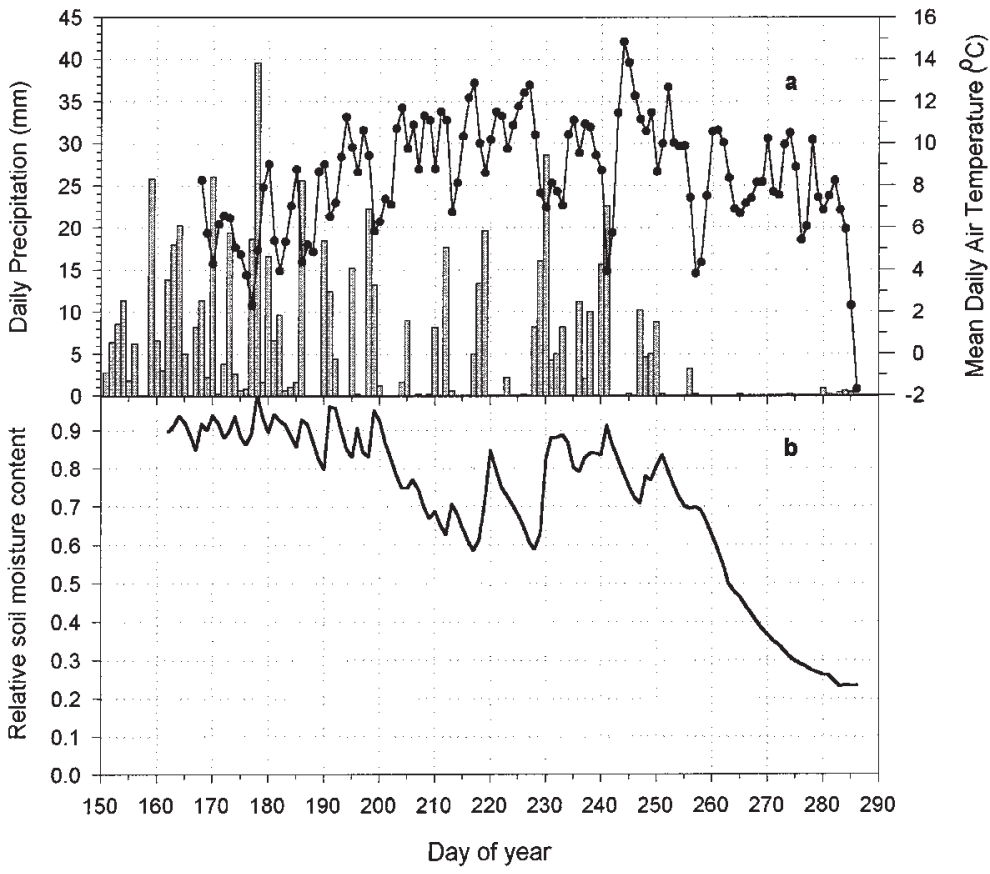

Figure 2. Comparison of seasonal trends in daily precipitation, mean daily air temperature (a) and relative soil moisture content at $30 \mathrm{~cm}$ depth (b).

reached, $\Psi$ increased slowly compared to the rapid fall in the morning. $F_{\mathrm{d}}$ in $P$. abies and $P$. cembra increased later and the maximum daily values were much lower than those of $L$. decidua. It is interesting to notice that when VPD was high at night $(1-3 \mathrm{hPa})$ there was a detectable sap flux occurring in L. decidua as shown in day 190 in figure 4. The other two species however did not show nocturnal transpiration.

Table III. Results of the statistical tests used to detect significant differences between time of the season (results differ from species to species), species and individuals regarding the data for $\Psi_{\mathrm{pd}}$ and $\Psi_{\mathrm{m}}$.

\begin{tabular}{lll}
\hline & $\begin{array}{c}\text { Predawn water } \\
\text { potential }\left(\Psi_{\mathrm{pd}}\right)\end{array}$ & $\begin{array}{c}\text { Minimum water } \\
\text { potential }\left(\Psi_{\mathrm{m}}\right)\end{array}$ \\
\hline Time of season* & & \\
L. decidua & $p<0.001$ & $p<0.001$ \\
P. abies & $p=n s$ & $p<0.01$ \\
P. cembra & $p=n s$ & $p=n s$ \\
Species* & $p<0.0001$ & $p<0.0001$ \\
Individuals & $p=n s$ & $p=n s$ \\
& &
\end{tabular}

* Kruskal-Wallis test, ${ }^{\#}$ Wilcoxon test.

\subsection{Seasonal variation in hydraulic resistance}

Sapwood-specific hydraulic conductance $\left(1 / R_{\text {soil-needle }}\right)$ and hydraulic resistance $\left(R_{\text {soil-needle }}\right)$ were calculated for the three species during the study period (figure 5) and showed different trends for each of the species studied. In L. decidua, $R_{\text {soil-needle }}$ increased constantly throughout the month of July, reaching its maximum $(0.6 \mathrm{MPa}$ $\mathrm{dm}^{-1} \mathrm{~h}$ ) at the end of July (day 211) and then decreasing during August. In P. abies, after some initial fluctuations, $R_{\text {soil-needle }}$ increased from July to August reaching its maximum $\left(0.45 \mathrm{MPa} \mathrm{dm}^{-1} \mathrm{~h}\right)$ at the end of August (day 235). P. cembra showed a highly fluctuating trend reaching its maximum $\left(0.51 \mathrm{MPa} \mathrm{dm}^{-1} \mathrm{~h}\right)$ on day 211 only to decrease sharply in August. Regression lines for $R_{\text {soil-needle }}$ were good for all cases of L. decidua and $P$. abies but only for two of P. cembra.

\subsection{Pressure-volume curves}

Pressure-volume curves for $L$. decidua were derived during five different days from the end of June to the beginning of August and two curves for P. cembra were derived at the beginning of August (day 213). 


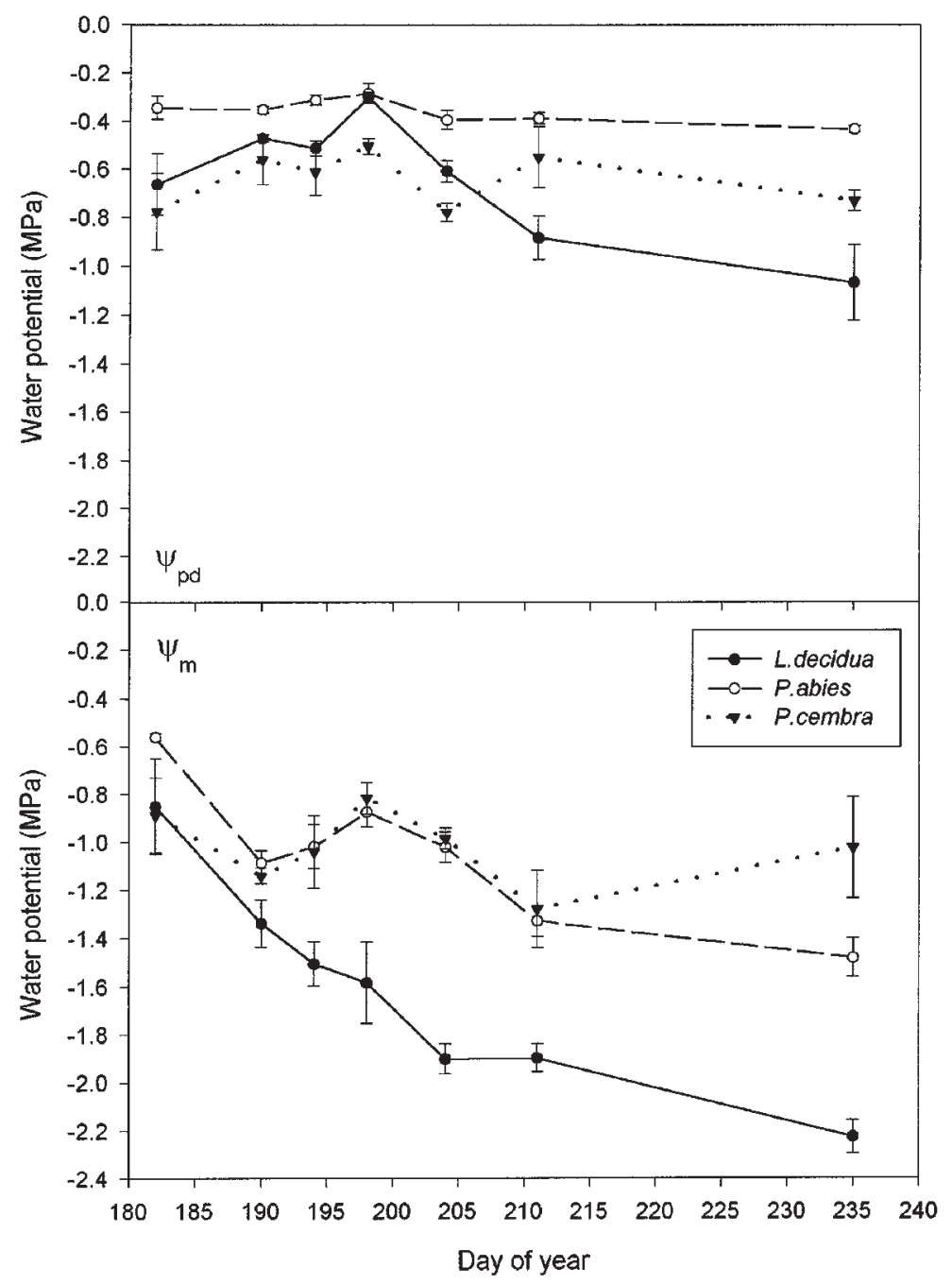

Figure 3. Variations of predawn water potential $\left(\Psi_{\mathrm{pd}}\right)$ and minimum water potential $\left(\Psi_{\mathrm{m}}\right)$ for L. decidua, P. abies and P. cembra during the study period. Bars $=1 \pm$ SE.

A number of parameters estimated from the pressurevolume curves are shown in figure 6. Both osmotic potential at full turgor $\left(\Psi_{\pi 100}\right)$ and water potential at turgor loss point (WPTLP) reached their maximum value on day 197 in L. decidua, before decreasing to their minimum at the beginning of August (day 214). The values obtained on day 213 for P. cembra were slightly higher.

The relative water content at turgor loss point (RTLP) and the maximum elastic modulus derived from the pressure-volume curves $\left(\varepsilon_{\max }\right)$ in L. decidua increased during the study period reaching their maxima at the beginning of August.
P. cembra showed a much lower value than L. decidua on day 213 for both, RTLP and $\varepsilon_{\max }$.

\section{DISCUSSION}

\subsection{Pressure-volume curves}

The main aim of the research was to assess the extent of osmoregulation in L. decidua and the compared responses to water availability of two co-occurring evergreen species. We concentrated on L. decidua as a previous study [1] on P.abies pressure-volume curves had 


\begin{tabular}{|c|c|c|}
\hline $\begin{array}{ll} & \text { PAR } \\
\cdots & \text { Temp } \\
\cdots- & \text { VPD }\end{array}$ & $\begin{array}{l}\text { Sap flux } \\
- \text { L. decidua } \\
- \text { - P. abies } \\
\text { - P. Pembra }\end{array}$ & $\begin{array}{l}\text { Water potential } \\
\rightarrow-\text { L. decidua } \\
\multimap-\text { P. abies } \\
-\quad \text { P. cembra }\end{array}$ \\
\hline
\end{tabular}

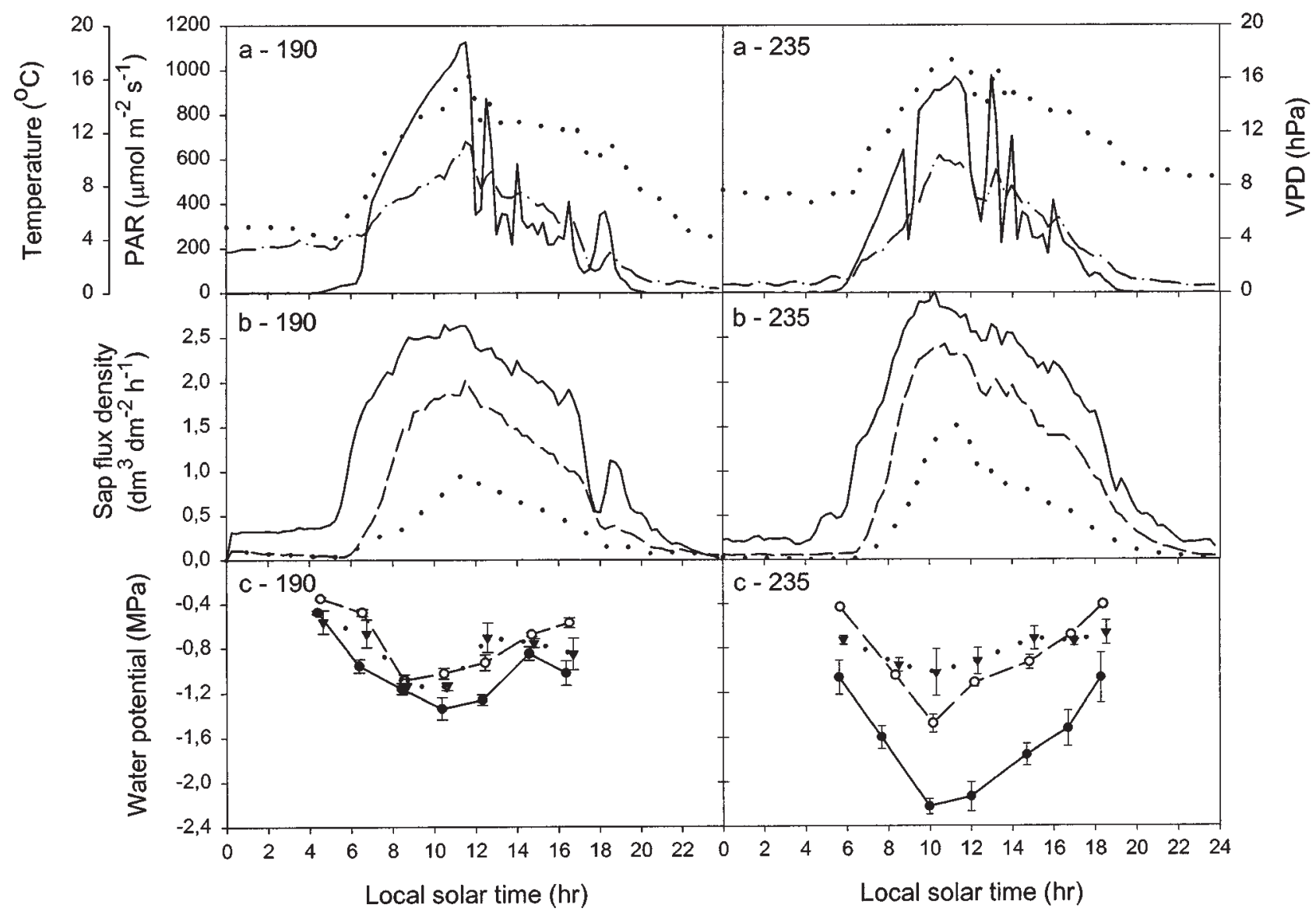

Figure 4. Daily fluctuations of environmental conditions (temperature, PAR, VPD) (a) in relation to sap flux density $\left(F_{\mathrm{d}}\right)(\mathrm{b})$ and shoot water potential ( $\Psi$ ) (c). Days 190 (9 July) and 235 (23 August). Bars $=1 \pm$ SE.

shown that no osmoregulation occurred in this species and no further experiments seemed necessary. In P. cembra, pressure-volume curves were very difficult to derive because of very high resin emissions during the dehydration phase and early attempts were unsuccessful.

We realise that the number of curves at our disposal is not enough for an in-depth study of the behaviour of the species. However, comparison of pressure-volume curves of $L$. decidua during the growing season allowed us to suggest whether osmoregulation had occurred or not. The latter is a process by which cell turgor is main- tained by means of increases in cell solute content (lowering $\Psi_{\pi}$ ) in response to water stress $[17,24]$ or when new organs are expanding $[24,32]$. It may be a very important mechanism for maintaining physiological activity as $\Psi$ falls, although some authors report it may be of little importance in conifers [16].

The decrease in $\Psi_{\pi 100}$ by about $0.6 \mathrm{MPa}$ was indicative of osmoregulation (figure $6 a$ ). This brings about a substantial decrease in WPTLP which in turn could enhance the water extraction capacity of the species (figure $6 a$ ). 

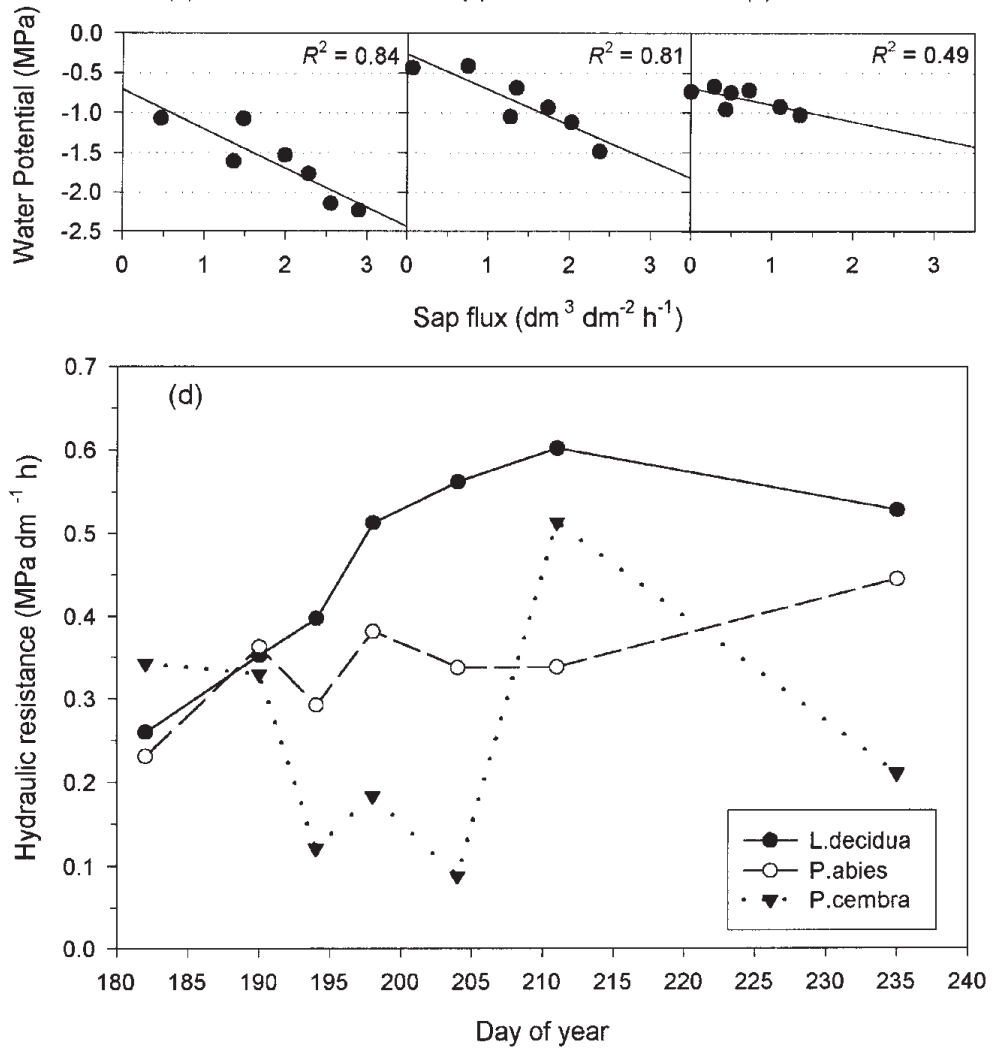

Figure 5. Comparison of hydraulic conductance in L. decidua (a), P. abies (b) and P. cembra (c) on day 235 (23 August). Seasonal variations in hydraulic resistance $(R)$ for $L$. decidua, $P$. abies and $P$. cembra are shown below in (d).

Since stomata conductance is maintained higher also under water deficit, leaf water potential decreases more than in absence of osmoregulation.

A lower leaf water potential means also a stronger decrease in xylem water potential due to the "propagation" of the water potential gradient among different plants compartments. A lower xylem water potential means, in turn, a lower water potential up to the fine roots. Since the water uptake depends also on the capacity to decrease the water potential, osmoregulation, in the end, should have the effect of increasing the water uptake capacity. Moreover, osmotic adjustment should allow to maintain turgor in root cells at lower water potential [27 in 32], leading to a more effective root elongation. Plants can, therefore, explore a greater volume of soil increasing the capacity of water uptake.

At the same time an increase in the elastic modulus of the cell wall $\left(\varepsilon_{\max }\right)$ has been observed, a feature usually associated with the capacity to withstand low water potentials (figure 6c).
It is also important to notice that between day 200 and day 214 there was a progressive decrease in precipitation and relative soil moisture (figure $2 b$ ) which is likely to have increased the water stress to which the trees were subjected. Hence the species enhanced its water uptake ability in mid-summer when the occurrence of moderately water deficits is most likely.

It would be risky to draw definite conclusion about the reasons for the occurrence of osmoregulation with the few curves we have derived but nonetheless they allow us to make some considerations. It seems unlikely that osmoregulation be the effect of ontogenetic changes since a parallel experiment conducted the same year [6] clearly showed that needle growth in L. decidua finished on days 188-190 well before the beginning of the decrease in $\Psi_{\pi}$ we have found. In fact on the first day of measurements (day 180) needles and shoots were still expanding [6] but $\Psi_{\pi 100}$ was higher than some weeks later (figure $6 a$ ). It should have been the opposite if an ontogenetic cause was involved. Furthermore, it has 


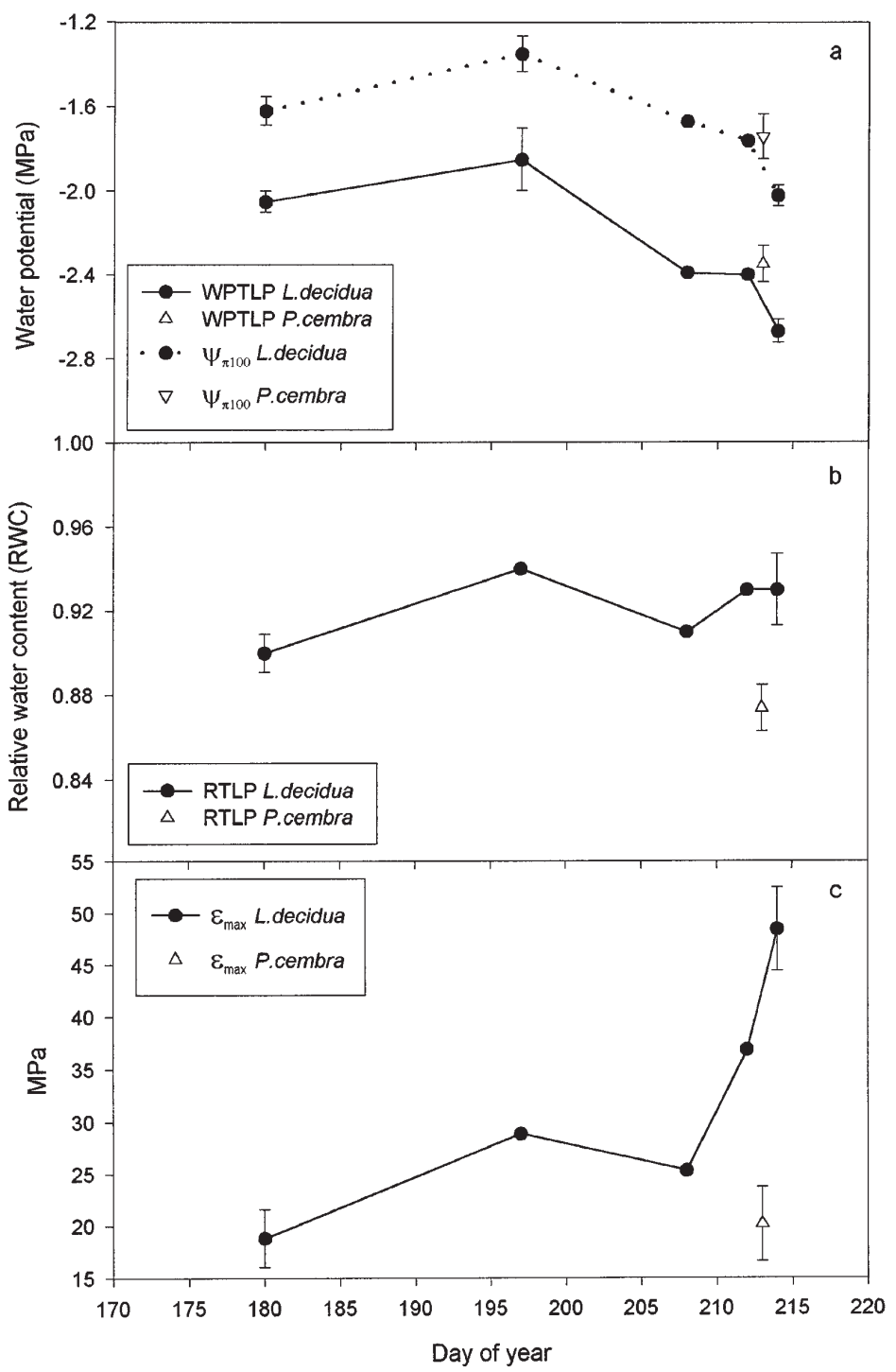

Figure 6. Seasonal trends for WPTLP and $\Psi_{\pi 100}$ (a), RTLP (b) and $\varepsilon_{\max }$ (c) as obtained from the analysis of the pressure-volume curves. Bars $=1 \pm \mathrm{SE}$ apart from values for day 208 and 212 in which they are absent since only one value was available.

been reported [24] that if plants are hardened by exposure to larger diurnal fluctuation in humidity and solar radiation (as it occurs at high altitude) the capacity of osmoregulation may remain unchanged or increase with age without water stress being involved.

\subsection{Daily shoot water potential and sap flux density variations}

Values of $\Psi_{\mathrm{m}}$ in $P$. abies were less negative than in similar studies conducted in other parts of the Alps [23] but more negative than those found at the same site the year before [2]. Moreover, $\Psi_{\mathrm{m}}$ was above the turgor loss point, which at the alpine treeline was found to be relatively constant throughout the growing season at about $-2.8 \mathrm{MPa}$ [1]. Relatively high values of $\Psi_{\mathrm{m}}$ suggest that stomatal control may occur well above the threshold of significant loss of xylem functionality in conifers growing under similar environmental conditions, found to be between -2.5 and $-3 \mathrm{MPa}$ [4]. Daily variations of VPD and $F_{\mathrm{d}}$ in L. decidua were visibly coupled (figure 4). This does not only occur in diurnal hours 
but also during the night and early morning provided VPD has a value of $1 \mathrm{hPa}$ or higher. This behaviour might be explained by the fact that cuticle conductance is rather high leading to a detectable nocturnal transpiration in relation to changes in VPD.

In all species $F_{\mathrm{d}}$ appears to be especially well correlated to VPD below the threshold of 7-8 $\mathrm{hPa}$ but when VPD is higher, the high stomatal sensitivity leads to a reduction of the expected $F_{\mathrm{d}}$ (see day 190 in figure 4 ) as already observed in a precedent study [2].

Variations of daily $\Psi$ in P.abies and P. cembra are closely coupled to variations in VPD and photosynthetic active radiation (PAR) (figure 4). Daily water potential variations (especially $\Psi_{\mathrm{m}}$ ) in L. decidua appear to depend on seasonal meteorological trends rather than daily ones as in P.abies and P.cembra. This is probably ascribable to internal physiological adjustments associated with osmoregulation. This is consistent with the results of another study [35] which concludes that deciduous species (L. decidua) use almost exclusively groundwater while evergreen species ( $P$. abies and P. cembra) use rainwater to a larger extent. The same study demonstrated that L. decidua develops a deep root system which allows utilisation of water sources in the deepest and wettest soil layers which are precluded for instance to P. abies because of its shallow root system.

The lower $\Psi_{\mathrm{pd}}$ measured in L. decidua at the end of July and in August might depend on nocturnal transpiration which prevents that an equilibrium between plant and soil be achieved during the night. Therefore the extractive capacity of the tree cannot be inferred from the analysis of $\Psi_{\mathrm{pd}}$ only but VPD and $F_{\mathrm{d}}$ must also be taken into account.

As expected, under non-limiting soil moisture conditions, L. decidua exhibited a $F_{\mathrm{d}}$ higher than the other two evergreen species.

\subsection{Hydraulic resistance}

It is unlikely that significant cavitation of water in the xylem occurred in these species. Even in L. decidua with the lowest $\Psi_{\mathrm{m}}$, the measurements of $\Psi_{\mathrm{m}}$ in this study and in an earlier one [2] are all well above the threshold of $\sim 3.0 \mathrm{MPa}$ which is when most (but not all) conifer species undergo a consistent loss in xylem conductivity [4]. The increase in overall hydraulic resistance $R$ in L. decidua is likely to be caused by increased resistance at the soil-root interface. It appears that this may be the way that soil moisture influences species also at the treeline. In function of its lower $\Psi_{\mathrm{m}}$, L. decidua is able to uptake more water in drier conditions than do P.abies and P. cembra which appear to be more susceptible to water shortage. Thus the results confirm what had already been found in a previous study [2] that despite high precipitation, soils at high altitude can become physiologically dry because they are shallow, discontinuous and highly permeable.

\subsection{Conclusions}

Data presented suggests that L. decidua is able to accumulate solutes within cells decreasing the osmotic component of water potential. This behaviour may allow the species to maintain a high stomatal conductance at lower water potential. Osmoregulation is rarely documented in conifers but L.decidua might be an exception perhaps because of its deciduous habit. We do not know yet whether low altitude ecotypes show a similarly pronounced capacity in accumulating solutes but it might be speculated that the shorter growing season and the lower soil water capacity might lead to an enhancement of the osmoregulation capacity in high altitude trees.

Compared to other two co-occurring conifers, L. decidua seems to be more adapted to continue carbon assimilation when mild water deficit conditions occur and seems to be less sensitive to soil water shortage as well.

Although it is not possible to draw definitive conclusions from this study, it can be imagined that if precipitation rate, regimes and cloudiness should change towards more xeric conditions as hypothesised recently [36], L. decidua might be advantaged and a change in high altitude forest composition might occur.

Acknowledgements: This research was carried out with the financial support of the Ministry of University and Scientific and Technological Research (MURST) funds ex $40 \%$. Special thanks go to Fausto Fontanella, Roberto Menardi and Giuseppe Sala of the Centre of Alpine Environment, San Vito di Cadore, for the precious technical support. We would also like to thank three anonymous reviewers for their comments and suggestions.

\section{REFERENCES}

[1] Anfodillo T., Casarin A., Variazioni stagionali nelle relazioni idriche di rametti di abete rosso lungo un gradiente altitudinale, in: Anfodillo T., Urbinati C. (Eds.) Ecologia delle foreste di alta quota, Proc. XXX Corso di Cultura in Ecologia, University of Padova, 1993, pp. 143-171.

[2] Anfodillo T., Rento S., Carraro V., Furlanetto L., Urbinati C., Carrer M., Tree water relations and climatic variations at the alpine timberline: seasonal changes of sap flux and 
xylem water potential in Larix decidua Miller, Picea abies (L.) Karst. and Pinus cembra L., Ann. Sci. For. 55 (1998) 159-172.

[3] Chapin III F.S., Körner Ch., Arctic and alpine biodiversity: patterns, causes and ecosystem consequences, Trends Ecol. Evol. 9 (1994) 45-47.

[4] Cochard H., Vulnerability of several conifers to embolism, Tree Physiol. 11 (1992) 73-83.

[5] Crawford R.M.M., Polar and altitudinal limits to tree survival, in: Crawford R.M.M. (Ed.), Studies in plant survival: ecological case histories of plant adaptation to adversity, Blackwell Scientific Pub., Oxford, 1989, pp. 77-103.

[6] Dandrea M., (1999) Dinamica di accrescimento di rami e foglie in conifere al limite superiore del bosco, Final theses at the University of Padova, 1999, p. 30.

[7] Dawson D.E., Spatial and physiological overlap of three co-occurring alpine willows, Funct. Ecol. 4 (1990) 13-25.

[8] Del Favero R., De Mas G., Lasen C., Paiero P., Il pino cembro nel Veneto, Regione del Veneto, Dip. Foreste. (1985) 85.

[9] Grabbher G., Gottfried M., Pauli H., Climate effects on mountain plants, Nature 369 (1994) 448.

[10] Grace J., Tree lines, Phil. Trans. R. Soc. Lond. B, 324 (1989) 233-245.

[11] Grace J., James J., Physiology of trees at treeline, in: Alden J., Mastrantonio J.L., Odum S. (Eds.), Forest development in cold climate, Plenium Press, New York, 1993, pp. $105-114$.

[12] Granier A., Une nouvelle methode pour la mesure de flux de seve brute dans le tronc des arbres, Ann. Sci. For. 42 (1985) 193-200.

[13] Guisan A., Holten J.I., Spichiger R., Tessier L., Potential ecological impacts of climate change in the Alps and Fennoscandian Mountains, Editions des Conservatoire et Jardin Botaniques Geneve, Geneva, 1995.

[14] Hattenschwiler S., Körner Ch., Responses to recent climate warming of Pinus sylvestris and Pinus cembra within their montane transition zone in the Swiss Alps, J. Veg. Sci. 6 (1995) 357-368

[15] Holtmeier F.K., The upper timberline: ecological and geographical aspects, in: Anfodillo T., Urbinati C. (Eds.) Ecologia delle foreste di alta quota, Proc. XXX Corso di Cultura in Ecologia, Universtity of Padova, 1993, pp. 1-26.

[16] Joly R.D., Zaer J.B., Alteration of cell-wall water content and elasticity in Douglas-fir during periods of water deficit, Plant Physiol. 83 (1987) 418-422.

[17] Jones H.G., Plants and microclimate, 2nd edition. Cambridge University Press, 1992.

[18] Körner Ch., Impact of atmospheric changes on alpine vegetation: the ecophysiological perspective, in: Guisan A., Holten J.I., Spichiger R., Tessier L., (Eds.), Potential Ecological Impacts of Climate Change in the Alps and Fennoscandian Mountains, Editions des Conservatoire et Jardin Botaniques Geneve, Geneva, 1995, pp. 113-120.

[19] Krauchi N., Potential impacts of climate change on forest ecosystems, Eur. J. For. Path. 23 (1993) 28-50.
[20] Kubiske M.E., Abrams M.D., Pressure-volume relationships in non-rehydrated tissue at various water deficits, Plant, Cell Environ. 13 (1990) 995-1000.

[21] Kullman L., Short-term dynamic approach to tree-limit and thermal climate: evidence from Pinus sylvestris in the Swedish Scandes, Ann. Bot. Fenn. 25 (1986) 219-227.

[22] Ladiges P.Y., Some aspects of tissue water relations in three populations of Eucalyptus viminalis Labill., New Phytol. 75 (1975) 53-62.

[23] Lu P., Biron P., Breda N., Granier A., Water relations of adult Norway spruce (Picea abies (L.) Karst.) under soil drought in the Vosges mountains: water potential, stomatal conductance and transpiration, Ann. Sci. For. 52 (1995) 117-129.

[24] Morgan J.M., Osmoregulation and water stress in higher plants, Ann. Rev. Plant Physiol. 35 (1984) 299-319.

[25] Parker W.C., Pallardy S.G., The influence of resaturation method and tissue type on pressure-volume analysis of Quercus alba L. seedlings, J. Exp. Bot. 38 (1987) 535-549.

[26] Ritchie G.A., Shula R.G., Seasonal changes of tissuewater relations in shoots and root systems of Douglas fir seedlings, Forest Sci. 30 (1984) 538-548.

[27] Sharpe R.E., Davies W.L., Solute regulation and growth by roots and shoots of water-stressed maize plants, Planta 147 (1979) 43-49.

[28] Scholander P.F., Hammel H.T., Bradstreet E.D., Hemmingsen E.A., Sap pressure in vascular plants, Science 148 (1965) 339-346.

[29] Schulte P.J., Hinckley T.M., A comparison of pressurevolume curve data analysis techniques, J. Exp. Bot. 36 (1985) $1590-1602$.

[30] Tranquillini W., Physiological ecology of the alpine timberline, Ecological Studies 31, Springer-Verlag, Berlin, 1979.

[31] Turner N.C., Techniques and experimental approaches for the measurement of plant water status, Plant and Soil 58 (1981) 339-366.

[32] Turner N.C., Adaptation to water deficits: a changing perspective, Aust. J. Plant Physiol. 13 (1986) 175-190.

[33] Tyree M.T., Hammel H.T., The measurement of the turgor pressure and the water relations of plants by the pressure-bomb technique, J. Exp. Bot. 23 (1972) 267-282.

[34] Tyree M.T., MacGregor M.E., Petrov A., Upenieks M.I., A comparison of systematic errors between the Richards and Hammel methods of measuring tissue-water relations parameters, Can. J. Bot. 56 (1978) 2153-2161.

[35] Valentini R., Anfodillo T., Ehleringer J.R., Water sources and carbon isotope composition $\left(\mathrm{d}^{13} \mathrm{C}\right)$ of selected tree species of the Italian Alps, Can. J. For. Res. 24 (1994) $1575-1578$.

[36] Wanner H., Beniston M., Approaches to the establishment of future scenarios for the alpine region, in: Guisan A., Holten J.I., Spichiger R., Tessier L. (Eds.), Potential Ecological Impacts of Climate Change in the Alps and Fennoscandian Mountains, Editions des Conservatoire et Jardin Botaniques Geneve, Geneva, 1995, pp. 87-95.

[37] Wardle P., An explanation for alpine timberline, New Zealand J. Bot. 9 (1971) 371-402. 